\title{
El transhumanismo: el triunfo del culturalismo y el fin de la selección natural
}

\author{
doi: 10.52749/fh.v2i2.2
}

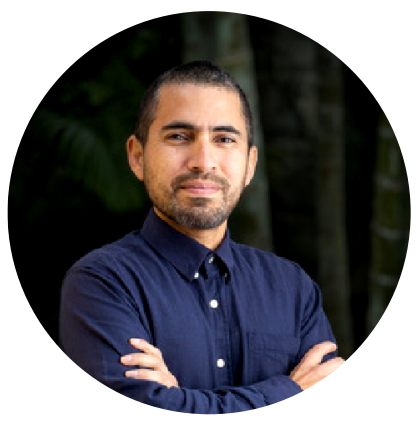

\section{HENRY LLANOS CHILET ID https://orcid.org/0000-0002-6023-8489}

Bachiller en ingeniería de sistemas y egresado de la Maestría de Filosofía de la Ciencia de la Universidad Nacional Mayor de San Marcos, Perú. Presidente de la Asociación Peruana de Ateos (APERAT). Miembro del Instituto de Extrapolítica y Transhumanismo (IET) y de la Sociedad Secular Humanista del Perú (SSH).

\section{henry.llanos@gmail.com $\quad 0$ @henryllanoschilet}

Resumen. Nuevamente enfrentados el discurso biologicista, ese de la psicología evolucionista y el programa de la sociobiología, y el discurso neoculturalista, ese que tiene la marca "negra" del constructivismo y sus afines desde su nacimiento, pugnan por predominar en la academia con un claro balance a favor del último. En este artículo se muestra que la verdadera dicotomía no es entre biología y cultura, como viene pregonando el biologicismo, sino entre la selección natural y los procesos culturales. Vamos hacia un estado donde aquello que llamamos "cultura" desplazará completamente a los genes. Pero, lo que muchos no habían visto, es el real poder transformador de la cultura desde nuestros inicios como fuerza predominante en la evolución humana y en nuestro comportamiento. Podemos decirlo con seguridad: somos animales culturales y el transhumanismo es, en sí mismo, un discurso culturalista.

Palabras clave: Biologicismo, Culturalismo, Selección Natural, Cultura, Transhumanismo, Posthumanismo.

\section{Una esencia del Transhumanismo}

Mucho se ha dicho sobre el transhumanismo como un movimiento cultural multidisciplinario donde la ciencia, la filosofía (en sus diversas ramas, especialmente la ética), enfoques socio-políticos y, especialmente, la tecnología se unen para darle vida. Es, principalmente, un discurso futurista sobre la evolución del ser humano y el inevitable paso del homo sapiens sapiens hacia un estado que se denomina, dentro de este movimiento, como "posthumano".

Este artículo no se centrará en brindar definiciones exactas. En su lugar se visibilizarán cualidades esenciales de esta corriente cultural (muy diversificada, por cierto) que nos servirán para reforzar la tesis central del artículo. Una actitud general de todos los transhumanistas es que "no ven la naturaleza humana como un fin en sí mismo (...) Por el contrario, no es más que un punto en un camino evolutivo y podemos aprender a reconfigurarla de formas que estimemos como deseables y valiosas" (Max More, 2013, pág. 4).

En el transhumanismo, pues, el concepto de naturaleza humana se diluye. Sus representantes, si siguieran el estilo de la filosofía continental del siglo $X X$, podrían muy bien proclamar "la muerte de la na- turaleza humana". Pero ¿Qué es eso que se hace llamar naturaleza humana?

\section{La Naturaleza humana}

Este concepto filosófico encierra aquello que el "ser humano" (otro concepto filosófico) tiene por "esencia". En términos prácticos, y para no caer en una larga divagación historiográfica, puede considerarse la "naturaleza humana" como aquellas cualidades que diferencian a la especie biológica "homo sapiens" de los otros animales.

Es evidente que tenemos cualidades especiales. Hauser consideraba que tenemos un conjunto de 4 cualidades específicas que llamaba "humanicidad": la computación generativa, la combinación promiscua de ideas, la capacidad de convertir nuestras percepciones en símbolos mentales y el pensamiento abstracto (Hauser, 2009). Todas estas cualidades son de naturaleza mental y no tanto fisiológicas. Nos diferenciamos, pues, por nuestra mente.

Pero el transhumanismo no ve esta diferencia como algo estático ni guarda lealtad a ninguna "esencia" del ser humano, sino que llama a trascenderla. El transhumanismo es progresista, anti-conservador, busca el mejoramiento de nues- 
tras capacidades a través de la tecnología. Y la tecnología no es más que una "porción" de la cultura humana.

Todo el "diseño estructural" (muy entre comillas esto, porque no hay ningún diseñador) de nuestro cuerpo es producto de la evolución por selección natural, incluido el cerebro donde residen nuestras capacidades mentales especiales. Pero hay una parte del cerebro que se construye mayormente por la interacción con otros humanos. En esa parte no sólo se ubica nuestra memoria de largo plazo (nuestros recuerdos y habilidades), sino que da mayor resolución a nuestras percepciones tanto internas (sentimientos) como externas (sistema sensorial). Es allí donde reside, pues, lo que somos como "seres humanos" y que Damasio (2010) Ilama "el sí mismo autobiográfico".

\section{El hombre: animal cultural}

Esa parte del cerebro es la corteza cerebral y en los humanos es estructuralmente muy especial a diferencia de la de otras especies que también la poseen. Se puede decir, con mucha seguridad, que ésta es la parte que nos hace humanos y donde reside físicamente la "humanicidad" de Hauser.

También se puede decir que ese fenómeno que llamamos cultura surge inherente e inevitablemente de la interacción con los otros humanos. El medio ambiente del ser humano no fue la mítica sabana africana, sino el entorno cultural que emergió de sus interacciones grupales; ya sea de pocas decenas, en la edad de piedra, o de millones de individuos en el periodo histórico; y que crea los nichos artificiales donde siempre nos hemos desenvuelto.

Al formarse la corteza cerebral, principalmente por la interacción con otros humanos, al ser ésta la residencia de nuestra "humanicidad" y al emerger la cultura de esa interacción entre humanos, se puede decir que somos animales culturales más que cualquier otra cosa.

Si bien la capacidad de producir un neocórtex, así como la naturaleza gregaria de los homínidos, provienen de la evolución por selección natural, la misma corteza cerebral (en sí) crece y se interconecta bajo la tiranía de la cultura, lejos de las presiones selectivas de la selección natural. Puede que haya algunos tipos de procesos de selección dentro de los grupos y sociedades humanas, pero serían más bien parte de una selección cultural.

Hacia el posthumanismo: la evolución en nuestras manos

El cambio (o "movimiento" de los griegos antiguos) algo inherente en la metafísica de nuestro universo. Las cosas nunca son estáticas. Por tanto, la evolución -como forma de cambio- jamás se detiene. Lo que varía es el tipo de evolución: desde la que tiene causas enteramente naturales (proceso 1) hasta la causada por factores culturales (proceso 2). Son dos procesos intrínsecamente distintos con mecanismos diferentes, lo que justifica diferenciarlos epistémicamente.

El proceso 1 se llama "evolución por selección natural" (ESN). Se da a nivel de los genes, es direccionalmente vertical (de progenitores a vástagos) y no es planificada conscientemente. El proceso 2, en cambio, lo llamaremos "evolución cultural" (EC). Se da a nivel de la interacción de individuos (a través de los comportamientos, principalmente en el aprendizaje social), puede ocurrir en direcciones verticales, horizontales $u$ oblicuas en relación con los linajes genéticos y siempre es planificada en algún grado (Robert Boyd, 1985).

En consecuencia, la EC tiende a ser más rápida que la ESN, tiene una mayor capacidad adaptativa general y provoca una firme adaptación a nivel de grupo de individuos, nivel donde la evolución por selección natural apenas tiene efectos.

El paso de una a otra no es abrupto, se da suavemente a través de un período donde ambas formas coexisten y -lo que es más importante, porque esto es la causa de las controversias- no en la misma intensidad o relevancia.

Predecimos aquí la "muerte" de la ESN, aquel mecanismo que formó la materia prima de nuestros cuerpos, pero no de nuestros mismos cuerpos y lo que somos en sí actualmente. En el futuro, si el ser humano no se autodestruye, todo el proceso evolutivo de las entidades biológicas será capturado por la EC y puede que las mismas entidades biológicas sean reemplazadas por otras distintas: será el fin de la biología tal como la conocemos.

La EC ya está aquí con mucha intensidad. No solo dirige el desarrollo de nuestra plastiquísima corteza cerebral (desde el momento en que el neonato ve la luz), sino que afecta al epigenoma de los fetos mucho antes del nacimiento. Esto es así porque sabemos que el medio ambiente del ser humano no es ni la sabana africana ni las cavernas de la prehistoria, sino los poblados y las ciudades que hemos construido, con todas sus costumbres, hábitos, cosmovisiones, ideologías y ecologías que supervienen. Miremos donde miremos, allí está la cultura.

Como bien se ha mencionado, también se incluyen 
las ecologías creadas por la cultura. Piénsese por ejemplo, si uno vive en Lima-Perú, en los acantilados convertidos en verdes malecones, en el espacio que le hemos robado al mar construyendo autopistas y puentes, en el sistema ecológico completamente artificial que hemos creado en nuestros parques, donde muchas especies migran en lo que de otra forma sería un desierto. Hemos creado un hábitat artificial donde nuevas presiones selectivas surgen en estas especies, interactuando con el humo de los carros o la actitud de los limeños respecto a ellas, entre otros. Presiones que no solo afectan la biología de esas especies de animales, si no, la nuestra propia.

O también, por ejemplo, piénsese en la conquista de los ámbitos extraterrestres en el futuro. En la terraformación de Marte ¿Se cree acaso que replicaremos el ámbito salvaje natural de la Tierra? ¿O construiremos más bien un ámbito sumamente artificial más parecido a nuestras ciudades con una naturaleza completamente domesticada? Este ámbito, que no se parecerá en casi nada a la sabana africana donde se produjo el proceso de hominización, creará nuevas presiones selectivas de naturaleza completamente cultural que seguirán modificando no solo nuestros hábitos, corteza cerebral y epigenoma, si no nuestro mismo genoma. La cultura, pues, se está "encarnando" en la biología y tomará completamente la dirección de su evolución.

En efecto, es posible referirse a modificación cultural del genoma. El transhumanismo [1], como puede verse, implica los métodos de edición del genoma humano a través de la tecnología para vencer al envejecimiento o transitar de una medicina netamente curativa a una de mejoramiento. Este proceso se hará de una manera finalista, donde el objetivo se da de una forma planificada y consciente siguiendo agendas políticas, ideológicas y enmarcadas dentro de una ética transhumanista (todos estos son agentes culturales). Y no sólo se modificará el genoma humano; si no, a la larga, el de todas las especies vivas de nuestro medio circundante en nuestros nuevos ambientes extraterrestres terraformados y por qué no - en la Tierra misma. La evolución biológica por selección natural será historia.

Evolución biológica guiada y causada por la cultura: un proceso que nos acompañó desde el inicio

Para muchos, el enfoque dado en las líneas anteriores puede resultar novedoso, pero no invero- símil. Sin embargo, aún hay más. Lo que muchos no habían advertido es que la evolución guiada por la cultura ha estado desplazando y minimizando a la ESN desde los albores de la humanidad. No tanto a través de un proceso finalista siguiendo "agendas globales" sumamente planificadas como sucederá en el futuro próximo (planificación en alto grado), sino a través de procesos emergentes de la gregarización humana similares a los que hacen evolucionar nuestros lenguajes o a las fuerzas invisibles que regulan el mercado en el modelo liberal. Estos procesos crean las convenciones que hacen funcionar a nuestras lenguas o mercados. En este aspecto se parecen en algo al proceso no finalista de la ESN. Sin embargo, sostenemos que sólo es una fase de transición hacia una evolución cultural enteramente planificada. El discurso biologicista -ese de la psicología evolucionista y del programa de la sociobiología- intenta minimizar el rol de la cultura en el proceso de evolución. Son aún fervientes creyentes de la selección natural como componente importante para explicar el comportamiento sistemático de nuestras sociedades actuales y de las personas que en ella viven. Creen que los cambios atávicos que produjo la ESN en la prehistoria o incluso antes (durante el proceso de hominización) tienen una persistencia tenaz en nuestros cerebros y sus neocórtex. Su fe es análoga a creer que un castillo de arena persistirá a las olas marinas por decenas de años. Porque así son las conexiones interneuronales de nuestra corteza cerebral, tan persistentes como una estructura hecha de arena de mar. En discursos biologicistas aún más radicales se cree que la cultura no puede cambiar algo más allá de lo que las estructuras persistentes formadas por la ESN le permiten.

En cambio, el discurso neo-culturalista (Llanos, 2021) minimiza el rol de la ESN (aunque no lo anula por completo) y le da mucha más importancia a los factores sistémicos y estructurales, propios del desenvolvimiento de las sociedades humanas, para explicar la constitución corporal actual y el comportamiento del ser humano como individuo y como grupo. Todo esto siguiendo la línea históricofuturista predicha en la tesis de este artículo, donde la cultura humana capturará todo proceso de cambio.

En el neo-culturalismo la evolución cultural puede rebasar con creces las estructuras formadas por la ESN, guiando o causando el proceso evolutivo. Esto queda cada vez más confirmado por los muchos ejemplos que el quehacer científico va acumulando sobre procesos de evolución biológica 
causados por la cultura humana.

La cultura empieza a mostrar su verdadero poder transformador que llega incluso a los genes. Ya no se habla sólo de la creación de cientos de razas de perros (canis familiaris), de cómo creamos el maíz gigante y los plátanos, de cómo las zanahorias se volvieron de color naranja debido al fervor patriótico holandés o de los miles de ejemplos de la llamada "selección artificial" (que no es otra cosa más que una forma de selección cultural). Ni de las modificaciones planificadas en el genoma de muchas especies de plantas y animales a través de la ingeniería genética que se hacen actualmente. Se discute ahora el cambio rapidísimo en el genoma humano impulsado por la cultura, gracias a los avances en genética evolutiva desde los años 90 del siglo pasado.

Ha habido cambios genéticos humanos sustanciales en los últimos 50 mil años, con posiblemente hasta un $10 \%$ de los genes humanos afectados (Williamson et al., 2007).En tan solo los últimos 10,000 años, la revolución agrícola, la domesticación de animales y el aumento en la densidad humana en los centros urbanos (con sus novedosos hábitos culturales), fueron una fuente importante de selección en nuestra especie modificando nuestro genoma y nuestros cuerpos: hubo una rápida evolución esquelética y dental en las poblaciones humanas, aparecieron nuevas respuestas genéticas a las dietas (casi siempre creadas por la cultura) y a las enfermedades, por una exposición a patógenos que depende de la densidad poblacional en las nuevas urbes y por el continuo flujo de individuos entre éstas (Laland et al., 2010).

Todo esto aceleró la evolución biológica humana mediante una gran cantidad de selección positiva reciente, con una velocidad de cambio genético que ha aumentado en los últimos 40.000 años. Se sabe que las poblaciones más grandes generan más mutaciones nuevas y beneficiosas seleccionadas (Hawks et al., 2007).

La expresión de los genes (epigenoma) que construyen el cerebro humano también sufrió importantes cambios por los desarrollos culturales descritos, produciendo importantes modificaciones estructurales en éste (Kim, 2003).

Entre los muchos ejemplos documentados (en toda la literatura anterior) de todos estos cambios en la estructura genética y cerebral de la especie humana causada por su cultura podemos mencionar:

- La serie de mutaciones en la enzima lactasa hace tan solo 9 mil años, que permite que la leche sea digerible durante la edad adulta en algunas poblaciones que se dedicaron a la producción de lácteos con distintas frecuencias.

- La resistencia a la malaria debido a la práctica cultural de cultivar ñame en algunas poblaciones del África. Las poblaciones que cultivan este tubérculo tienen tasas más altas del gen que produce la anemia falciforme, una enfermedad peligrosa que, sin embargo, genera resistencia natural contra la malaria.

- La predominancia de la diabetes tipo 2 en los polinesios. Se descubrió que los polinesios tienen una tasa alta de frecuencia del gen PPARGC1A que es responsable de los altos índices de diabetes tipo 2. Esto se produjo por las costumbres exploratorias de sus ancestros que, al soportar viajes largos en el mar sin mucha comida, desarrollaron un metabolismo ahorrativo que genera más rápido depósitos de grasas en el cuerpo.

- La invención de la cocina alteró la evolución de nuestras mandíbulas y esmalte dental. Y esto a su vez permitió evolucionar a los lenguajes articulados al sofisticarse los sonidos humanos con la modificación estructural del tracto vocal (D. E. Blasi, 2019).

- La aparición del lenguaje creó procesos de selección que favorecieron la complejización del cerebro humano y del sistema nervioso.

\section{Conclusiones: ¿Hacia dónde vamos?}

Podemos resumir lo anterior diciendo que todo el entorno del ser humano es la cultura donde se desenvuelve y que emerge de su proceso de gregarización, a esto se le ha llamadoparadigma del "animal cultural". Tradicionalmente se pensaba que la cultura y la genética eran dos procesos separados, pero los investigadores se están dando cuenta de que están íntimamente relacionados y que cada una influye indisolublemente en la progresión natural de la otra. Sin embargo, no es que la evolución por selección natural sea el mismo proceso o incluya a la evolución cultural: el que uno haya surgido del otro no implica relación de identidad o inclusión, como hemos visto.

La cultura ha estado indisolublemente ligada a la evolución de la especie humana y esto no lo niega el actual discurso biologicista. Pero este discurso va más allá y sostiene que hay una persistencia, de naturaleza enteramente biológica, de los cambios producidos por la ESN en las estructuras cerebrales, que sigue afectando gran parte de nuestro comportamiento. Nos dice que para comprender las 
estructuras sociales y el comportamiento humano [2] es necesario tener muy en cuenta los cambios genéticos producidos en el paleolítico o incluso antes, como si la mente humana se mantuviera más o menos estática desde esas épocas. El biologicismo de la psicología evolucionista no quiere ver la importancia del neocórtex en la determinación del comportamiento humano, la gran plasticidad de ésta, ni la rapidez con que puede darse el proceso de evolución (incluso a nivel genético) en pocos miles de años. Es candidata pues, de no encontrarse los módulos cognitivos y los correlatos neurales persistentes que predice, a derivar en pseudociencias.

En algunos humanistas seculares, la preferencia por el discurso biologicista sobre el neo-culturalista se da (en parte) por la pertenencia del primero al grupo de ciencias duras, que usan metodologías más exactas no replicadas aún en las ciencias humanas o culturales. También porque el culturalismo, con su primo el constructivismo, han nacido en medio del terreno fangoso del estructuralismo, la hermenéutica y el postmodernismo. Pero incluso la flor de loto puede nacer en medio de los pantanos y no por ello deja de ser hermosa. Por todo lo investigado aquí, el neoculturalismo está más cerca de esa verdad anhelada para comprendernos como seres humanos.

La frase "la cultura no puede modificar lo que dictaminan los genes" va quedando como un dogma del discurso biologicista.

El papel de la cultura va más allá: es el impulsor predominante de la evolución humana desde la época en que nacimos como especie. La cultura está llegando a reemplazar a la evolución genética como el sistema principal de herencia humana y predecimos que llegará a reemplazarla por completo. Esto no solo pasará en los humanos, sino en todo el planeta: será el fin de la evolución por selección natural, quedando la biología evolucionista como un bonito recuerdo de nuestra cuna. Y si el proyecto transhumanista de la "desbiologización" del ser humano se lleva a cabo, será el fin de toda la biología.

En nuestros futuros ambientes terraformados, en los exoplanetas o sus satélites, no habrá evolución por selección natural, sino pura evolución cultural. Sin embargo, si llegáramos a construir una ingeniería del tiempo, tal vez la Tierra quede como un gran museo, tal vez construyamos burbujas museos donde la ESN siga operando solo con fines didácticos o recreativos; tal vez virtualicemos todo el proceso y lo pasemos a grandes computadores. El futuro irá por ese rumbo: el fin de la Biología.

Nuestro futuro como especie humana o posthumana no sólo depende de si logramos un completo dominio de la Física en todos sus niveles, sino de que las ciencias culturales de naturaleza blanda, logren el mismo nivel de predicción que las ciencias duras o aún más.

[1] El transhumanismo también implica, como segunda vía, el volcado de la mente humana a una máquina cibernética no biológica. Con la cual cualquier tipo de evolución biológica (sea natural o cultural) quedaría sólo en zoológicos o museos futuristas.

[2] Incluye comprender las estructuras raciales, el género, etc.

\section{Referencias}

Blasi, D.E.; Moran, S.; Moisik, S. R.; Widmer, P.; Dediu, D.; Bickel, B. (2019). Human sound systems are shaped by post-

Neolithic changes in bite configuration. Science 363(6432), eaav3218, https://doi.org/10.1126/science.aav3218

Damasio, A. (2010). Y el cerebro creó al hombre. Destino.

Hauser, M. (2009). El Origen de la Mente. Investigación y Ciencia (398), pp. 4-11.
Hawks, J.; Wang, E. T.; Cochran, G.M.; Harpending, H.C.; Moyzis, R.K. (2007). Recent acceleration of human adaptive evolution. $\begin{array}{llll}\text { PNAS, } & 104 & \text { (52), }\end{array}$ https://doi.org/10.1073/pnas.0707650104

Laland, K.; Odling-Smee, J.; Myles, S. (2010). How culture shaped the human genome: bringing genetics and the human sciences 
together. Nature Reviews Genetics, 11 137-148. https://doi.org/10.1038/nrg 2734

Kim, S. (2003). Thought in a hostile world. Malden: MA: Blackwell. Llanos, H. (2020). Explicaciones para la brecha de género en la

Cuarta Revolución Industrial. Futuro Hoy, 1(1), 16-18. https://doi.org/10.52749/fh.v1i1.4

More, M; Vita-More, N. (2013). The Transhumanist Reader: Classical and Contemporary Essays on the Science, Technology, and
Philosophy of the Human Future. John Wiley \& Sons. Richardson, P. Boyd, R. (1985). Culture and the evolutionary process. University of Chicago Press.

Williamson, S.H.; Hubisz, M.J.; Clark, A.G.; Payseur, B.A.; Bustamante, C.D.; Nielsen, R. (2007). Localizing Recent Adaptive Evolution in the Human Genome. Plos Genetic, https://doi.org/10.1371/journal.pgen.0030090.

\section{Cómo citar este artículo:}

Llanos, H. (2021). El transhumanismo: el triunfo del culturalismo y el fin de la selección natural. Futuro Hoy, 2(2), 13-18. https://doi.org/10.52749/fh.v2i2.2

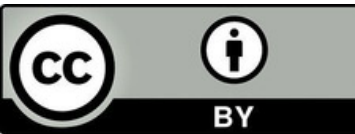

Esta obra está bajo licencia internacional Creative Commons 4.0 Reconocimiento 4.0. 